\title{
Recognizing our authors
}

\author{
Kazuhiko Takeuchi ${ }^{1}$
}

(c) Springer Japan KK, part of Springer Nature 2021

As editor in chief of the international journal Sustainability Science, I am proud to announce winners of the 2020 Sustainability Science Best Paper Awards. We conduct the yearly awards to recognize contributions of researchers that further enhance understanding of sustainability science and demonstrate high standards of scientific quality.

For this award, we considered all papers published in 2020 excluding note and comments, editorials, message article and papers authored by a member of the committee. From a total of 107 eligible papers published in 6 issues of 2020, four winners ( 1 outstanding paper and 3 honorable mentions) have been chosen following our selection process. Our entire advisory board along with selected active editors are encouraged to nominate papers which members feel make a particularly good contribution to the advancement of sustainability science. The nominated papers are then ranked based on reviewer impressions and downloads, among other criteria, and then are hand selected by our nominating committee. Links and short descriptions of the winning papers are shared below.

I congratulate the authors for their hard work on this significant accomplishment, as well as Thomas Elmqvist from Stockholm University, Sweden and Keisuke Hanaki from Toyo University, Japan, for their extended support from the beginning of the process. We believe authors deserve recognition for diligent work beyond a citation count and other article metrics. Conversely, this serves as an indicator for our readership to find high-quality, new research publications.

This award provides acknowledgements in the form of a $€ 200$ book voucher from Springer for winning papers. The winning papers are:

Kazuhiko Takeuchi

sustsci.eo@gmail.com

1 Institute for Global Environmental Strategies (IGES), Kanagawa, Japan
Outstanding article

For the paper entitled:

Environmental justice and the SDGs: from synergies to gaps and contradictions

Authors: Mary Menton, Carlos Larrea, Sara Latorre, Joan Martinez-Alier, Mika Peck, Leah Temper and Mariana Walter.

November 2020, Volume 15, Issue 6

Short description:

The sustainable development goals (SDGs) aim to 'leave no one behind' yet failure to embed environmental and social justice within the SDGs creates trade-offs and contradictions which can exacerbate injustices. This article reviews progress in environmental justice (EJ) frameworks in recent years, arguing for the need to move beyond a focus on the four principles of mainstream EJ (distribution, procedure, recognition, and capabilities) towards a more intersectional decolonial approach to environmental justice that recognizes the indispensability of both humans and non-humans. EJ frameworks, and the SDGs, should recognize power dynamics, complex interactions among injustices, and listen to the different 'senses of justice' and desires of theorists, activists, and other stakeholders from the Global South. The article examines how EJ frameworks are, or fail to be, incorporated in the SDGs with a focus on the food-water-health nexus, climate-energy, conservation, and poverty and inequality. It calls attention to the 'elephant in the room'-the failure to go beyond GDP but instead include economic growth as a goal (SDG8). The authors conclude that sustainable degrowth and intersectional decolonial environmental justices would create better conditions for the transformative changes needed to reach the broader aims of the SDGs.

\section{Honorable mention}

For the paper entitled:

Towards understanding interactions between Sustainable Development Goals: the role of environment-human linkages

Authors: Jörn P. W. Scharlemann, Rebecca C. Brock, Nicholas Balfour, Claire Brown, Neil D. Burgess, 
Miriam K. Guth, Daniel J. Ingram, Richard Lane, Juliette G. C. Martin, Sylvia Wicander and Valerie Kapos.

November 2020, Volume 15, Issue 6

Short description:

Only 10 years remain to achieve all Sustainable Development Goals (SDGs) globally, so there is a growing need to increase the effectiveness and efficiency of action by targeting multiple SDGs. The SDGs were conceived as an 'indivisible whole', but interactions between SDGs need to be better understood. Several previous assessments have begun to explore interactions including synergies and possible conflicts between the SDGs, and differ widely in their conclusions. Although some highlight the role of the more environmentally focused SDGs in underpinning sustainable development, none specifically focuses on environment-human linkages. Assessing interactions between SDGs, and the influence of environment on them can make an important contribution to informing decisions in 2020 and beyond. Here, we review previous assessments of interactions among SDGs, apply an influence matrix to assess pairwise interactions between all SDGs, and show how viewing these from the perspective of environment-human linkages can influence the outcome. Environment and environment-human linkages influence most interactions between SDGs. Our action-focused assessment enables decision-makers to focus environmental management to have the greatest impacts and to identify opportunities to build on synergies and reduce trade-offs between particular SDGs. It may enable sectoral decision-makers to seek support from environment managers for achieving their goals. We explore cross-cutting issues and the relevance and potential application of our approach in supporting decision-making for progress to achieve the SDGs.

\section{Honorable mention \\ For the paper entitled:}

Creating a space for place and multidimensional wellbeing: lessons learned from localizing the SDGs

Authors: Eleanor J. Sterling, Pua'ala Pascua, Amanda Sigouin, Nadav Gazit, Lisa Mandle, Erin Betley, John Aini, Simon Albert, Sophie Caillon, Jennifer E. Caselle, Samantha H. Cheng, Joachim Claudet, Rachel Dacks, Emily S. Darling, Chris Filardi, Stacy D. Jupiter, Alexander Mawyer, Manuel Mejia, Kanoe'ulalani Morishige, Winifereti Nainoca, John Parks, Jamie Tanguay, Tamara Ticktin, Ron Vave, Veronica Wase, Supin Wongbusarakum and Joe McCarter.

July 2020, Volume 15, Issue 4

Short description:

Achieving sustainable development globally requires interdisciplinary efforts and diverse, inclusive perspectives. Global goals shape priorities and actions, creating cascading impacts on well-being at the local level by directing critical resources and implementing programs intended to achieve progress towards these metrics. Thus, it is important to understand how global indicators that inform sustainable development intersect with the values, conceptions, and priorities of well-being at other scales. This is particularly important as many countries gear up for measuring and monitoring well-being indicators beyond the conventional, growth-focused metrics. This study compared the Sustainable Development Goal (SDG) indicators with factors contributing to well-being in Pacific Islands to see how the SDGs could inform sustainable development in this region. The research shows both overlaps and significant gaps. While some aspects important in the Pacific are well represented in the SDGs (e.g., those related to human health and access to infrastructure and finances), other dimensions are not, such as those regarding connections between and across peoples and places, and recognition of Indigenous and local knowledge. As a result, conventionally generated indicators may result in misdiagnosis and the design of on-the-ground interventions that have unintended and negative outcomes. The paper provides lessons learned to foster equitable and holistic sustainability approaches and outcomes, and to support efforts to bring strong evidence and solutions for sustainability policy challenges across decision-making scales.

\section{Honorable mention}

For the paper entitled:

Seeds of good anthropocenes: developing sustainability scenarios for Northern Europe

Authors: C. Raudsepp-Hearne, G. D. Peterson, E. M. Bennett, R. Biggs, A. V. Norström, L. Pereira, J. Vervoort, D. M. Iwaniec, T. McPhearson, P. Olsson, T. Hichert, M. Falardeau and A. Jiménez Aceituno.

\section{March 2020, Volume 15, Issue 2}

Short description:

Imagining alternative futures is a technique that is often used to develop robust strategies for making decisions today. Most imagined environmental futures are bleak or consider a narrow range of interventions such as technology or environmental policy, which limits the opportunities for people to develop strategies to move towards more desirable futures. This paper extends and applies an approach to imagining desirable futures developed in the Seeds of Good Anthropocenes project (goodanthropocenes.net) that is based on envisaging the movement of existing, potentially transformative sustainability initiatives from the margins of societies to the mainstream. The research described in the paper brought together sustainability practitioners, artists and academics to imaged desirable sustainability transitions in Northern Europe. By developing scenarios based on existing, but marginal initiatives, and considering what types of conditions would enable these initiatives to flourish, the authors were able to identify system characteristics, such as gender dynamics, governance, and disaster response, that may 
play a key role in sustainability transitions but are currently under-explored in global environmental scenarios. Such scenario methods are useful for not only creating more diverse futures, but also identifying issues to include in research or modelling of sustainability transitions.

I extend my congratulations to all the winning authors.

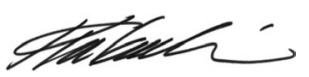

\author{
Kazuhiko Takeuchi \\ Editor-In-Chief
}

\section{References}

Menton M, Larrea C, Latorre S, Martinez-Alier J, Peck M, Temper L, Walter M (2020) Environmental justice and the SDGs: from synergies to gaps and contradictions. Sustain Sci 15:1621-1636
Raudsepp-Hearne C, Peterson GD, Bennett EM, Biggs R, Norström AV, Pereira L, Vervoort J, Iwaniec DM, McPhearson T, Olsson P, Hichert T, Falardeau M, Jiménez Aceituno A (2020) Seeds of good anthropocenes: developing sustainability scenarios for Northern Europe. Sustain Sci 15:605-617

Scharlemann JPW, Brock RC, Balfour N, Brown C, Burgess ND, Guth MK, Ingram DJ, Lane R, Martin JGC, Wicander S, Kapos V (2020) Towards understanding interactions between Sustainable Development Goals: the role of environment-human linkages. Sustain Sci 15:1573-1584

Sterling EJ, Pascua Pua'ala, Sigouin A, Gazit N, Mandle L, Betley E, Aini J, Albert S, Caillon S, Caselle JE, Cheng SH, Claudet J, Dacks R, Darling ES, Filardi C, Jupiter SD, Mawyer A, Mejia M, Morishige Kanoe 'ulalani, Nainoca W, Parks J, Tanguay J, Ticktin T, Vave R, Wase V, Wongbusarakum S, McCarter J (2020) Creating a space for place and multidimensional well-being: lessons learned from localizing the SDGs. Sustain Sci 15:1129-1147

Publisher's Note Springer Nature remains neutral with regard to jurisdictional claims in published maps and institutional affiliations. 